\title{
Elementos identitarios indígenas desde la autogestión comunitaria en tiempos de la pandemia de COVID-19: los jóvenes shipibos voluntarios del Comando Matico
}

\author{
Sandra Balvín Bellido \\ Estudiante de Antropología en la Pontificia Universidad Católica del Perú (PUCP). \\ e-mail: sandra.balvin@pucp.pe
}

\section{Resumen}

Frente a las muchas pérdidas humanas que trae consigo la emergencia sanitaria causada por la COVID-19 y el abandono estatal, un grupo de jóvenes shipibos y mestizos de Yarinacocha - Pucallpa, formaron un colectivo voluntario denominado Comando Matico; para enfrentar dicha emergencia a base de medicina ancestral shipiba. Estos jóvenes deciden actuar a pesar de las restricciones estatales, motivados por un carácter solidario que parece ser de raíz antigua entre los shipibos. El presente artículo, explora la construcción identitaria del grupo; que realiza una serie de prácticas de convocatoria para obtener el apoyo de la comunidad virtual a su labor voluntaria y de demanda ciudadana al Estado, entremezcladas y sostenidas en formas de auto representaciones particulares en el espacio virtual de Facebook. Esta construcción con fines prácticos en la virtualidad (orientada, como veníamos mencionando, a la autogestión indígena) está íntimamente vinculada al proceso de construcción identitaria offline. El contexto pandémico, es propicio para una renovación de la puesta en práctica de los conocimientos ancestrales shipibos; así como, para los jóvenes voluntarios que retoman la búsqueda del reconocimiento de su herencia ancestral, alimentando el mencionado proceso de construcción identitaria al mismo tiempo que fortalece la búsqueda de autonomía indígena -al menos en lo que respecta al ámbito de la salud.

\section{Palabras clave}

Emergencia sanitaria, abandono estatal, autogestión indígena, jóvenes shipibos, sabidurías ancestrales, solidaridad shipiba, identidades, autonomía indígena. 


\title{
Indigenous identity elements from community self-management in the times of COVID-19 pandemic: the young volunteer shipibos of the Matico Command
}

\author{
Sandra Balvín Bellido \\ Anthropology student at the Pontifical Catholic University of Peru (PUCP). \\ e-mail: sandra.balvin@pucp.pe
}

\begin{abstract}
With the many human losses brought about by the health emergency caused by the COVID-19 and state abandonment, a group of young Shipibo from Yarinacocha Pucallpa formed a voluntary group called Comando Matico, to face this emergency based on ancestral Shipibo medicine. These young ones decide to act despite state restrictions, motivated by what seems to be an ancient-rooted solidarity among the Shipibo. This article explores the identity construction of the group, which performs a series of convening practices to obtain the support of the virtual community for its voluntary work and citizen demand from the State, intermixed and sustained in particular forms of self-representations in Facebook's virtual space. This construction for practical purposes in virtuality (oriented, as we have been mentioning, to indigenous self-management) is intimately linked to the process of offline identity construction. The pandemic context, is conducive to a renewal of the implementation of ancestral shipibo knowledge; as well as, for the young volunteers that resume the search for recognition of their ancestral heritage, nurturing the referred process of identity construction at the same time that it strengthens the search for indigenous autonomy -at least with regard to the field of health.
\end{abstract}

\section{Keywords}

Health emergency, state abandonment, indigenous self management, young shipibos, ancestral wisdom, shipibo solidarity, identities, indigenous autonomy. 


\section{Introducción}

Con el incremento de los casos de COVID-19 en todas las regiones del país, que se dio progresivamente desde los primeros meses del 2020; también fueron aumentando las víctimas mortales del virus. La población shipiba de la Amazonía no se vio libre de la tragedia, que se fue magnificando por la falta de capacidad del Estado para lidiar con la pandemia desde el sistema de salud estatal, incluso en peores condiciones en la región amazónica.

Ante esta difícil situación, un grupo de jóvenes shipibos y mestizos de Yarinacocha (Pucallpa) decidieron enfrentar la emergencia sanitaria que los hospitales no alcanzaban atender - como ellos mismos denuncian en su página de Facebookaplicando sus conocimientos sobre medicina ancestral shipiba, usando plantas medicinales y masajes en todo el cuerpo. Así se conformó el colectivo de voluntarios Comando Matico, que gestiona el apoyo proveniente de la comunidad, de empresas públicas, entre otros para su labor, desde las redes sociales. En este espacio virtual de autogestión comunitaria surgen una serie de auto representaciones de la identidad shipiba que son el interés del que parte este trabajo.

El tema particular del presente trabajo, parte del interés académico por las representaciones de la identidad shipiba que se dan en las redes sociales (en este caso del Facebook del Comando Matico) y se formula desde la pregunta por las identidades de los jóvenes shipibos del Comando Matico contra la COVID-19; utilizando dichos espacios virtuales para la autogestión comunitaria. Partiendo de esta, se ha establecido como principal objetivo de la investigación: comprender el modo en que se configuran hoy las identidades shipibas en el grupo que conforma el Comando Matico, a partir del uso de las nuevas tecnologías de la comunicación para la autogestión comunitaria. Los objetivos secundarios que a su vez se desprenden del objetivo principal, son dos: por un lado, identificar cómo han venido representando sus identidades los jóvenes shipibos del Comando Matico en los medios y nuevas tecnologías de la comunicación; y por otro, explorar la forma en que entienden hoy sus identidades los jóvenes shipibos que conforman el Comando Matico.

\section{Identidades virtuales}

Según Hine "más que trascender el tiempo y el espacio, Internet puede ser representada como una instancia de múltiples órdenes espaciales y temporales que cruzan una y otra vez la frontera de lo online ${ }^{l}$ y lo offline ${ }^{2 "}$ (2004, p. 21). De hecho, es posible que la distancia deje de ser un obstáculo para la inmediatez de la difusión informativa o de la comunicación. Al mismo tiempo, supone un espacio interminable

\footnotetext{
1 Hace referencia a lo que sucede en la realidad virtual; en tanto, su uso por parte de las personas, se trate de formas de expresión, interacciones, relaciones sociales.

2 Hace referencia a todo aquello que sucede en la realidad social fuera del espacio virtual.
} 
donde lo uno como lo otro, puede llegar a darse entre grandes cantidades de usuarios simultáneamente y sin importar las diferentes localidades donde estos se encuentren. Este flujo constante entre el mundo físico y el mundo virtual genera cuestionamientos con respecto de la continuidad y autenticidad entre las identidades virtuales y las identidades offline.

Para responder a estas preguntas por la identidad, sin asumir que son problemas que únicamente aparecen en el ciberespacio, en tanto espacio de análisis social. Hine, plantea que la autenticidad identitaria se construye en un "desempeño discursivo que organiza las declaraciones de tal manera que procuren tal percepción [...]" (2004, p. 21); es decir, que la secuencia de interacciones o participaciones de los usuarios en lo virtual busca conformar un discurso con cierta coherencia sobre la existencia de una identidad auténtica detrás de lo virtual (en lo offline), de cara a la World Wide Web. Nos referimos, entonces, a una identidad que busca autenticarse ${ }^{3}$ permanentemente, como parte de su existencia en lo virtual, y que al mismo tiempo retroalimenta y contribuye a la construcción de la identidad offline del individuo. Las identidades virtuales son como identidades individuales que se construyen buscando representar una coherencia, probando su autenticidad desde un discurso en la virtualidad que implique al menos un doble movimiento continuo vinculado a la búsqueda de consistencia identitaria; la existencia online y la offline de los usuarios.

\section{Estado externo - extractivista}

Los territorios ancestrales de la población amerindia han sido históricamente, $\mathrm{y}$ en algunos casos siguen siendo, foco de decretos y medidas estatales que buscan justificar el ingreso y avance del mercado. Y su consecuente y progresiva degradación de los lugares de residencia que constituyen fuentes de recursos para la supervivencia y normal desarrollo de esta población (Kopenawa, 2013, p. 434). A pesar de los acuerdos internacionales firmados -como el Convenio 169 de la OIT- establecen que el Estado, debería alinear su proceder con los intereses de conservación de la Amazonía y los estilos de vida tradicionales de la población que la habita, este es de facto. Un Estado que aún viabiliza la extracción y depredación de los territorios que formalmente están bajo su propia protección, devela la existencia de un Estado extractivista.

Al mismo tiempo, este Estado extractivista está presente con servicios básicos como educación o salud, dentro de estos espacios geográficos, pero con debilidad. Justamente, estos dos servicios, derechos elementales de la ciudadanía, llegan con

\footnotetext{
3 Autenticarse. En este caso, hace referencia al proceso de confirmar la autenticidad de algo o alguien mediante una verificación de un agente externo (como sería el caso de que un organismo del Estado verifica la autenticidad de alguien como propietario de un inmueble), nos referimos específicamente a una intención de confirmar la autenticidad de la identidad propia en lo virtual sin la necesidad de que exista un proceso formal o instituido sino más bien todo lo contrario como parte del nuevo espacio para la construcción de la identidad individual que surgen en el mundo virtual.
} 
muchas deficiencias a las poblaciones de la Amazonía. Además de las carencias que comparten con otras regiones, en la inadecuada implementación del servicio de salud estatal; como infraestructura o número insuficiente de profesionales a disposición de la población; sobre todo en zonas rurales y no costeras (Alcalde-Rabanal, 2011). Dejando de lado los saberes de las poblaciones originarias y los beneficios que presentan. Si bien dentro del sistema de salud pública existe el enfoque intercultural; por ejemplo, que promueve la recuperación y uso de la medicina tradicional indígena (Política Sectorial de Salud Intercultural 2016 - 2021), las iniciativas al respecto son incipientes. No reconocen el lugar que tiene la población heredera de los saberes a recuperar y aplicar.

De este modo, los representantes del Estado, se posicionan como actores externos dejando de lado a la población. Por lo tanto, al momento de pensar en las instituciones y organizaciones que representan al Estado en la Amazonía; así como, su largo proceder en contra de muchos derechos de los pobladores de la Amazonía, hablamos de un Estado externo-extractivista.

\section{Vulnerabilidad histórica global}

Una manera amplia y enriquecedora de hablar de los desastres es a partir de la noción de riesgo de desastres de Diaz Caravantes, quien la define como la posibilidad de daño a la salud e integridad de una población expuesta y vulnerable ante una amenaza (2018, p. 17). Así, mientras la amenaza es la potencial ocurrencia de eventos físicos con efectos adversos sobre la población de un lugar, la exposición se refiere a la presencia de ciertos elementos que puedan propiciar estos eventos en el espacio amenazado. La vulnerabilidad sería, más bien, una predisposición como característica propia de los individuos o grupos afectados. Diaz Caravantes propone, a partir de ello, la noción de vulnerabilidad global, que vendría a ser la "predisposición al daño de los elementos expuestos - de una comunidad-como consecuencia de la conjunción de diversas dimensiones, individuales y colectivas, que limitan el acceso y movilización de recursos de los seres humanos y sus instituciones" (Díaz, 2018, p. 20). De este modo, el autor plantea que es difícil entender la vulnerabilidad física disociada de la política, económica, cultural o social.

A partir de esta última definición, la vulnerabilidad de un grupo, como la amenaza de muerte por COVID-19 que se vive en la actual pandemia, se puede entender mejor al ubicarla en una estructura de recursos económicos-sociales-culturales y políticos (MIDIS, 2019, p. 18); a partir de esta, surgen diferentes posibilidades de responder o protegerse frente a una amenaza determinada. En el caso de la población shipiba, hay que tomar en cuenta como se hace evidente en la descripción que hace Kopenawa de los yanomami que viven en una situación de pobreza tangible con respecto a Occidente, que si bien no es inherente y más bien producto de la ocupación histórica y progresiva de sus territorios por el mercado, no deja de colocarles en una posición desventajosa de la estructura de recursos socioeconómicos y político-culturales del país (Kopenawa, 2013, p. 428). 
Por eso, se puede considerar que los grupos socioculturales y étnicos del país, así como la población amerindia, se encuentran en una situación de vulnerabilidad histórica global. Además, de destruir sus territorios y depredar sus recursos; el ingreso del mercado a la Amazonía trae graves riesgos como: la muerte, la violencia, y esclavitud de la población; todo esto como parte del proceso de imposición de una lógica y un sistema estatal que minimiza los saberes y recursos indígenas frente a la cultura occidental.

\section{Autogestión comunitaria indígena}

Más allá de sus distintas significaciones históricas, la autogestión comunitaria puede entenderse ubicándose dentro de los márgenes de un estado nación. Según Boourdet, la transformación económica y política supone la "toma en sus manos, intermediarios y a todos los niveles, de todos sus asuntos por todos los hombres" (en Vázquez y Gómez, 2006, p. 155). De modo que, en el caso de las poblaciones indígenas, la autogestión supondría una independencia de lo estatal, sólo en el ámbito municipal, por razones de localización dentro del estado nación; pero, no de manera total por la demanda de recursos que provee en cierta medida el Estado para estos grupos. Bajo estas circunstancias, la autogestión se da de manera progresiva, ya sea desarrollándose en espacios para la educación intercultural o en programas de salud comunitaria e intercultural.

Según Vásquez y Gómez, la autogestión indígena "implica considerar diversos aspectos de la cultura, cosmovisión, organización social, lógica económica y sistemas de gobierno propios" (2006, p. 156); es decir, que se deben considerar las prácticas sociales propias de la herencia cultural de cada pueblo y no solo aspectos económicos o administrativos parciales. Además, para comprenderla hay que tomar en cuenta que, al ser una práctica comunitaria, las nociones de identidad étnica y autonomía indígena son centrales en este proceso (Vázquez y Gómez, 2006, p. 157). En este caso la autogestión indígena abarca solo el ámbito de la autogestión para la salud con miras a convertirse en un programa intercultural, pero su desarrollo implica la constante presencia de prácticas de auto representación identitaria del grupo de los jóvenes indígenas shipibos que conforman el colectivo Comando Matico, en el cual no deja de estar presente la noción de autonomía indígena.

\section{Identidad indígena y salud en la Amazonía}

A partir del análisis de una experiencia de formación de enfermeros interculturales (indígenas) en la Amazonía peruana, Cárdenas (2017) nos habla de la interculturalidad como una posibilidad de práctica crítica cuando parte de los movimientos indígenas como es el caso de la organización que estuvo a cargo del programa (AIDESEP). Según Tubino y Walsh, "cuando los movimientos indígenas incorporan en sus agendas el concepto de interculturalidad, este adquiere un significado propio, puesto que es 
implementado para lograr sus propios objetivos", una interculturalidad; además, en constante construcción. El programa, que inició en el 2005, estaba orientado a fortalecer los sistemas de salud indígena y a mejorar la calidad de la salud de su población. Para AIDESEP, el enfermero técnico en salud intercultural podría tender un puente entre el sistema médico occidental y el indígena de modo que ambos pudieran articularse para una mejor atención (Cárdenas, 2017). El desarrollo del programa fue posible por la autonomía con que contaba AIDESEP para elegir su propia plana docente, donde figuraban tanto especialistas médicos como especialistas indígenas y buscaba que ninguno de ambos conocimientos se posicionara sobre el otro. De esta manera, la interculturalidad aparece como un proyecto político para transformar las estructuras dominantes existentes creando nuevas formas de poder en el área de la salud. La propuesta de salud intercultural de AIDESEP -que parte de una experiencia únicamente circunscrita a tres localidades en la Amazonía peruana-, se da en el marco de normativas del MINSA que incorporan la interculturalidad como un enfoque transversal pero que no han logrado mejorar la calidad de la atención de la población indígena (Cárdenas, 2017).

En este marco amplio del Estado insuficiente de la salud intercultural en nuestro país se hace necesario tomar en cuenta el uso de la noción de identidad (indígena) que es la premisa de la idea de interculturalidad. Para esto nos sirve el análisis y problematización de una serie de "encuentros" interculturales entre grupos indígenas y el estado venezolano. A partir del registro de los diálogos que se dieron en dicho encuentro el autor cuestiona el uso de las nociones de cultura e identidad de las que partían los representantes del Estado venezolano y que muy probablemente puedan estar presentes en los espacios peruanos equivalentes. El autor explica que los principales desencuentros entre la población indígena y el Estado residen en la forma de entender ambas nociones de los representantes de este último, de acuerdo a una perspectiva que las entiende como realidades esenciales o determinadas en vez de procesos sociales. $\mathrm{Al}$ cosificarlas y colocarlas en el centro de las problemáticas de la salud se obvia el lugar de las redes complejas en las que se encuentran -como son las relaciones de larga data con occidente- las relaciones entre indios y criollos, entre otras. El autor explica que los representantes del estado venezolano terminan por crear una identidad que los pueblos indígenas - muchos interesados más bien en lograr el acceso a recursos occidentales como medicinas, profesionales médicos, etc.- buscan reproducir desde los esquemas occidentales sobre la manera de ser indígena que Ramos (The hypperreal indian, 1992) llamaría hiperreal (a partir de las propias aspiraciones morales occidentales de grupos indigenistas diversos). Así, el Estado termina por ignorar las demandas reales de los pueblos indígenas e imponer agendas propias que muy probablemente no implican la misma inversión por un lado y, por otro, mantienen a estos pueblos en una situación de doble sumisión (no tener voz y/o solo poder tenerla según los parámetros establecidos por el Estado). Sin dejar de considerar que los sistemas de salud en la Amazonía no pueden reemplazarse de ningún modo por el sistema occidental, si bien pueden muy bien complementarse (Clavijo, 2011). De modo de que, para pensar la salud indígena en la Amazonía hay que tener en cuenta por un lado que no ha estado siendo 
efectiva, con excepciones como la propuesta intercultural de AIDESEP que implica la intervención directa de los movimientos indígenas, y por otro que la articulación de las prácticas interculturales en la salud estatal no puede darse partiendo de un criterio que no asuma la cultura y la identidad de manera procesual y como fenómenos cuya definición práctica corresponde a los propios pueblos.

\section{Metodología}

Esta investigación se ha realizado en el contexto del espacio virtual debido a la imposibilidad de viajar a Yarinacocha, donde actúa el Comando Matico. Si bien la virtualidad no es nuestro objeto de estudio, sí es el espacio social en que buscaremos conocer las formas en que representan sus identidades los jóvenes shipibos del Comando Matico. Sin embargo, conocer estas prácticas de auto representación no resulta suficiente para acercarnos a cómo entienden o cómo dicen que entienden hoy sus identidades los jóvenes shipibos que conforman el Comando Matico. La estrategia metodológica utilizada descansa en la aplicación de dos técnicas distintas, ambas a través del uso de las tecnologías de la comunicación. En primer lugar, se hizo observación en el medio virtual: en el Facebook del colectivo de voluntarios que conforman el Comando Matico. Este es un espacio social donde el grupo interactúa con la comunidad virtual. Asimismo, se realizaron entrevistas a profundidad mediante video-llamadas a larga distancia. Las entrevistas se realizaron a tres de los cinco miembros fundadores del Comando Matico, por cuestiones de disponibilidad de tiempo, y sin poder considerar entrevistar a otros actores vinculados con el trabajo del grupo de voluntarios como representantes del Estado u ONGs que los han apoyado.

Al respecto es pertinente insistir que, en el contexto de una ausencia de relaciones cara a cara entre el investigador y aquellos sobre cuyas formas de auto representación y nociones identitarias propias se pretende conocer; la autoridad etnográfica encuentra otras formas de sostenerse. Existe un preámbulo analítico (teórico y metodológico) que le otorga al investigador una posición única entre los demás internautas para observar y registrar lo necesario para la investigación (Hine, 2004). Con respecto a la posibilidad de interactuar o participar en este espacio virtual, se decidió no hacerlo al no conseguir respuestas adecuadas durante el trabajo de campo.

Para la observación virtual se utilizó una guía de observación y registro de vídeos y fotografías publicadas en la página de Facebook del colectivo; y para las entrevistas a larga distancia por (videollamada), una guía de entrevista semiestructurada. A partir de estas se proponen códigos para sistematizar y analizar la información producida (LeCompté et al.). En la guía de observación y registro se describieron las interacciones en los videos y se registró los discursos de aquellos interactuando en los mismos. A partir de ambas fuentes de información se extrajeron patrones de las prácticas de auto representación para aunar su análisis al ser codificación (LeCompté et al.). Se utilizó también un cuaderno de campo virtual y un diario de campo en Google drive. 


\section{Línea del tiempo}

A partir de las entrevistas a profundidad que se realizaron a tres miembros del Comando Matico (Rafael García, Néstor Paiva y Alexander Shimpukat), que dieron el consentimiento necesario para realizar este trabajo, se realizó una breve línea de tiempo.

1. Momento previo, de "origen": en medio de noticias de pérdidas de vidas de muchos shipibos, artistas, activistas, e incluso alcaldes. Alexander se entera de la situación que vive la comunidad shipiba de Cantagallo en Lima; y que el gobierno había cercado por los altos números de contagiados de COVID 19, dejando así que todos los demás allí continuaran contagiándose y muriendo encerrados. La madre de Alexander se encontraba en Cantagallo y, preocupado, decide contactar a Néstor Paiva para buscar su apoyo.

2. Momento de conformación, "reunión de amigos" (15 de mayo del 2020): Néstor Paiva, también enterado de la situación alarmante que vivían los shipibos de Cantagallo, acude al llamado de Alexander y convoca, a su vez, a su amigo chamán Rafael García. Néstor y Alexander son amigos desde la adolescencia, época en la que ambos eran ya activistas. En esta reunión se acuerda tomar medidas ante la falta de apoyo del Estado y se decide recolectar la planta medicinal matico para enviar a Cantagallo.

3. Etapa de "recolección y envío": los tres amigos, junto a Jorge Soria -tío de Alexander y quien ya había tenido experiencia curando a base de matico y otras plantas medicinales a su cuñado- y Elmer Cairuna -quien prestó la conexión de internet- realizaron una transmisión en vivo. El objetivo de esta, era comunicar el envío de matico a Cantagallo, y también para convocar a la comunidad virtual a apoyarlos en la recolección de la planta; y para conseguir otros recursos con que apoyar a la comunidad de Cantagallo. Al mismo tiempo, querían difundir las propiedades curativas de la planta. En medio de esta transmisión vía el Facebook de Elmer Cairuna, los miembros fundadores del Comando Matico, movidos por "la emoción" invitan a todos aquellos en Yarinacocha que tengan síntomas de COVID-19 a buscarlos para someterse al tratamiento alternativo que proponen. Ese mismo día y al día siguiente -según cuenta Alexander- los medios los llamaron para entrevistarlos. Los cinco amigos, algo sorprendidos por la respuesta de la comunidad, se preguntaron qué hacer. Entonces, decidieron formar el colectivo que se define, según su misma página de Facebook, como "un grupo humano multidisciplinario de jóvenes indígenas, que luchamos para salir de esta pandemia mundial llamado COVID-19, demostramos la valentía y compromiso ante una autoridad que no atiende a la población vulnerable" aplicando sus conocimientos sobre plantas y medicina tradicional shipiba al tratamiento de la mortal enfermedad.

4. Etapa de "actividad sanadora": al recibir llamadas de aquellos con síntomas de COVID-19, los miembros del recientemente conformado Comando Matico comenzaron 
a ir a las casas de los enfermos a ayudarlos. Para aplicar la cura ${ }^{4}$, los miembros del Comando fueron en contra de los protocolos de prevención de contagio de COVID del Ministerio de Salud. En esta etapa, llegan a un momento pico. La cantidad de pacientes que los llamaban para buscar socorro era tanta, que debieron buscar un ambiente para trabajar. El párroco de Yarinacocha les permitió el uso de su local, y allí comienzan a recibir pacientes que se quedan internados hasta su recuperación. Hasta diciembre del 2020, curaron a más del $90 \%$ de los pacientes que trataron.

5. Etapa de "reducción de la actividad sanadora": se da una reducción del número de pacientes, debido al decrecimiento de contagios de la "primera ola" de COVID-19. Esto coincide con que el plazo para permanecer en el local de la parroquia se vence y deben trasladarse a un nuevo local en la comunidad intercultural de Bena Jema.

6. Etapa de "regreso a la labor sanadora": el Comando Matico, que había seguido trabajando en el local que la comunidad intercultural de Bena Jema les permitió usar mientras volvían a conseguir un local adecuado, retomó formalmente sus actividades.

\section{Resultados}

En este apartado se presentan los resultados de la sistematización del registro virtual sobre las formas de auto representación a partir de las 16 publicaciones en el Facebook del Comando Matico, registrados hasta la última semana de noviembre del 2020. Así como los videos que realizan distintos miembros del grupo de voluntarios agradeciendo las donaciones que recibe el grupo para su labor o pacientes que se han recuperado gracias al tratamiento en base a plantas medicinales como el matico entre otras.

\section{Prácticas}

El Comando Matico, ha desarrollado una serie de prácticas vinculadas entre ellas: las de convocatoria (a colaborar, a desobedecer, y a votar); así mismo las de autoidentificación o auto representación directa (como jóvenes maticos y como activistas); las de difusión del conocimiento ancestral, la presentación de testimonios; el registro de apoyos; y, finalmente las prácticas de demanda (de interculturalidad y de apoyo estatal).

El Comando Matico comenzó a gestionar su labor voluntaria a través de las prácticas de convocatoria. La primera que identificamos fue la convocatoria a colaborar a la comunidad virtual, por la cual invitan a la colaboración voluntaria: recolectando matico o apoyado con otros insumos o dinero. También identificamos una convocatoria a

\footnotetext{
Tratamientos a base de masajes en todo el cuerpo y vaporizaciones de matico y otros ingredientes naturales, a lo que se sumaban algunos medicamentos occidentales.
} 
desobedecer los protocolos estatales de seguridad sanitaria para poder salir a buscar matico, así como para buscar tratamientos alternativos. La tercera fue la convocatoria a votar por el grupo en redes sociales para que este pueda ganar un premio de la empresa Movistar; premio que les permitirá conseguir fondos para su labor voluntaria.

Entremezcladas con estas, los miembros del Comando Matico han desarrollado también prácticas de autoidentificación. La más común es la de autoidentificación como jóvenes maticos. Así se presentan, como jóvenes voluntarios que, aunque no tienen dinero, si cuentan con conocimientos sobre medicina ancestral shipiba y con un fuerte compromiso social. Una segunda práctica consiste en la autoidentificación activista; por lo que, se presentan como activistas y artistas o profesionales shipibos comprometidos con la comunidad.

A las anteriores prácticas se suman aquellas de difusión del conocimiento ancestral, la presentación de testimonios de los pacientes recuperados y el de registrar apoyos al colectivo. La primera de éstas, trata de la difusión de los conocimientos shipibos sobre medicina ancestral (plantas medicinales, explicación de sus usos y su identificación en videos) que permiten la recuperación de los pacientes del colectivo. Por otro lado, está la presentación de testimonios, a partir de la declaración de los mismos pacientes, así como del grupo de voluntarios, que muestran eficacia de sus tratamientos alternativos. El grupo de voluntarios, además, busca agradecer el apoyo que logran día a día con el registro de apoyo, de las organizaciones sin fines de lucro, empresas privadas, etc. Además del agradecimiento, se expresa también el compromiso sostenido de parte de los colaboradores.

Finalmente, los dos últimos patrones que se encontraron se refieren a prácticas dirigidas a demandar cuestiones específicas, pública y directamente al Estado. Una es la demanda intercultural y la otra la demanda de apoyo estatal. Mientras que la primera busca el apoyo económico e institucional para el proyecto de un hospital intercultural shipibo adecuadamente implementado en tanto iniciativa del Comando Matico. La segunda, en cambio, se refiere a la demanda directa al Estado de apoyo económico y en especias necesarias para la labor comunitaria y voluntaria actual del Comando Matico.

Se puede asumir, a partir del anterior registro y descripción de prácticas, que el Comando Matico utiliza su Facebook para convocar el apoyo de la comunidad virtual de modo que logren la autogestión; es decir, que puedan continuar con su labor a pesar de carecer de fondos y ante el abandono de un Estado ineficiente. La autogestión les permite, además, funcionar como una organización libre de la burocracia municipal y estatal; sin una estructura interna, sino más bien a partir del acuerdo y coordinación horizontal y continua entre sus miembros.

Además, de la labor central de aplicar un tratamiento alternativo contra la COVID-19, por medio de su Facebook también comparten con la comunidad virtual el conocimiento de herencia ancestral sobre plantas medicinales con el que realizan 
su labor. Las evaporaciones y los jarabes naturales que complementan con medicina occidental, y que les ha permitido la efectividad que los hospitales del Estado no han logrado, son parte de conocimientos que no estaban al alcance de la comunidad virtual antes de la labor de difusión del colectivo, o que al menos no era posible de obtener ante las largas búsquedas y comunicación virtual sostenida.

Podemos ver que las prácticas del Comando Matico en la virtualidad están orientadas al sostenimiento de la autogestión, y que están vinculadas a sus demandas políticas de reconocimiento del valor de su herencia cultural. A pesar de que dependen en alguna medida del Estado, al cual le demandan su apoyo, resulta evidente que a pesar de las dificultades parecen buscar conducirse a largo plazo hacia cierta autonomía, con seguridad hasta ahora al menos en lo que concierne al ámbito de la salud indígena en Yarinacocha-Pucallpa y sus alrededores y eventualmente en comunidades shipibas en Lima.

\section{Discurso}

Como se ha expuesto con anterioridad, las prácticas de auto representación que apoyan y se relacionan con las demás prácticas que encontramos en el registro virtual apuntan a una construcción identitaria por medio de la Internet que responde a sus necesidades de autogestión. Sin embargo, el proceso de construcción identitaria no puede -menos que- responder a una necesidad mucho más compleja.

La construcción identitaria que hemos visto, y que en la virtualidad responde a fines prácticos, sucede también como es de esperarse, en la realidad offline. Para acceder al modo en que entienden sus identidades los jóvenes shipibos del Comando Matico nos serviremos del análisis de su discurso. Por medio de las entrevistas a profundidad, explicaremos las nociones e ideas que tienen sobre su propia identidad. Por cuestiones de espacio no colocaremos aquí el detalle de la sistematización y análisis de las entrevistas, sino que daremos una explicación global de lo que nos han dejado saber sobre cómo entienden su propia identidad, incluyendo fragmentos de las entrevistas de la mayoría de los códigos.

Se describen los códigos mencionados, encontrados repetidamente en varias de las entrevistas en los próximos dos párrafos. En el primero, se presentan siguiendo un orden que responde a la narrativa de los entrevistados sobre cómo surgió el Comando Matico. Y, en el segundo, sin la necesidad de encontrar un orden en particular, agrupándolos simplemente como factores que hacen posible que surja la iniciativa de autogestión comunitaria.

El primer código identificado es el del control estatal ineficiente. Este código se refiere a la institucionalidad estatal -expresada tanto en los protocolos del MINSA, como en la vigilancia policial- como formas de control y protección social poco eficientes y restrictivas en el contexto de crisis sanitaria. 
Empezamos a hablar un poco, y me dice oye la única forma de apoyar es, ósea ahí Jorge Soria me dice que él le salvó a su suegro de la muerte, ya estaba abandonado, lo que decían no te acerques, los protocolos fueron las estrategias para que la gente pueda morir no [...] juntamos los tres, ahí veras tenemos fotos de los cuatro, están los primeros fotos son los cuatro que estamos ahí, ya a eso de las tres y hemos juntado casi todo el día no, escapándonos de la policía porque nadie podía salir inmovilización pero nosotros siempre hemos salido. (Néstor)

Un segundo código es el miedo. En este caso, el miedo se refiere al que tienen los shipibos de aplicar el conocimiento de la medicina tradicional ante las restricciones del sistema socioeconómico (en tiempo de crisis sanitaria) al poder de las farmacéuticas avaladas por dicho sistema.

Lo que pasa es que antes que conformemos este Comando ya algunos de los integrantes estábamos curándonos y curando con matico, pero la cuestión era, como todo era miedo no podíamos tampoco decir a todo el mundo mira estoy curando con esto, sino era cuidar un poco también nuestro conocimiento, porque curar sanar o mejorar una planta tradicional estas yendo contra las farmacéuticas, era un poco difícil de que pudiéramos mostrarlo. (Néstor)

El tercero, que se podría entender como una forma de sobreponerse ante el miedo mencionado, es la autogestión y resistencia. La autogestión comunitaria supone autonomía ante lo estatal (municipal o nacional), así como el prescindir de estructuras de organización vertical y mediación burocrática; mientras que la resistencia se relaciona a la búsqueda de autonomía indígena frente a un Estado que permite e incluso facilita la depredación de sus territorios, y cuyos servicios elementales no están pensados para la población indígena, manteniendo así un sistema de colonización cultural de sus formas de vida. Esta autonomía se da a partir de la puesta en práctica del conocimiento ancestral y/o la difusión de información.

[...] Y como necesitábamos más personas, lo que hicimos fue este, hay que llamar voluntarios porque en realidad necesitábamos voluntarios [...] y de donde sale el nombre bueno, los tres salimos, entonces hay que hacer nuestro propio Comando le digo no, ya pues será Comando Matico, entonces de ahí sale el Comando Matico, sin imaginar que podríamos lograr grandes cosas hasta en la actualidad, tenemos muy buenas proyecciones para que esta iniciativa que ha salido sea sostenible, siquiera que quede para algo y para las futuras generaciones que puedan recordar que no se necesita tanta plata para hacer cambios, que no se necesita tantos recursos para poder ayudar a un pueblo, que no se necesitan grandes proyectos de inversión para salvar a un pueblo, sino se necesita voluntad, tu conocimiento, y que puedas compartir, igual que la tierra que se comparte, y así nació este Comando Matico [...] justamente este nace, ya digamos del pueblo shipibo nosotros los shipibos nace para dar solución a problemas que han estado mucho tiempo, la 
desatención y salud a los pueblos indígena, y justamente sabíamos que no nos dan interés y no nos iban a atender y por eso es que hemos pensado en nuestro propio sistema de salud y cuidado y la idea es que en algún momento ves podamos ser autónomos, manejando nuestros propio sistema de educación, salud, administración, bueno etc. no, bueno suerte que hemos tenido que el estado nos ha escuchado y vamos a seguir lo que queremos hacer un hospital, y eso nosotros sabemos que el estado no nos toma en cuenta no estamos dentro de sus políticas públicas, y pues desde el Comando Matico queremos impulsar eso justamente y buscar aliados, así se puede trabajar conjuntamente, compartiendo conocimiento. (Néstor)

El cuarto código corresponde a la medicina o herencia ancestral, que implica el conocimiento de cuáles son y cómo se usan las plantas con propiedades medicinales en la Amazonía y que los tres entrevistados identificaron como su fortaleza en tiempos de crisis.

Finalmente, un quinto código es sobre los saberes ancestrales, pero en el sentido del resurgimiento del conocimiento indígena acompañado de la consciencia de que es importante mantener vivos los conocimientos o saberes ancestrales shipibos: plantas medicinales, lengua shipiba, tradición oral shipiba, solidaridad, etc.

Yo hablo shipibo [...] yo traduzco, interpreto en shipibo [...], si un pueblo pierde su lengua no hay no existe [...] para mí la lengua shipiba es lo que somos [...] la lengua es lo primordial, digamos vital [...] yo tengo una educación EIB [...] solo tuve clases de español y shipibo, pero no fueron clases de español o sea ni clases de shipibo, así aprendemos los shipibos (¿ósea la educación EIB no es solo un idioma sino que son los dos idiomas a la vez? - entrevistador) sí pues eso frustra no, así es pues...bueno es un poco largo también de cómo es que jóvenes de la ciudad han roto ese racismo, bueno eso es otra cosa ya, otra historia, bueno no otra historia sino acciones por identidad no, que estábamos muy discriminados, bueno yo hablaba shipibo desde niño siempre en el colegio nomás no hablaba por, bueno por, sería para otra entrevista [...] y creo que la lengua nos ha permitido mantener nuestro conocimiento [...] si es que mis padres o los shipibos hubieran dejado de hablar, no me lo hubieran dicho...nada no, ósea los cuentos de mi abuela, los cuentos que me contaba en shipibo, y era la única forma que me educara de esa manera, porque los cuentos son [...] son reales no, de la medicina, todo, entonces la lengua siempre tiene que seguirse no...y mantener, revitalizar, no solamente desde un enfoque educativo, hay varias formas de mejorar muchas necesidades educativas de las poblaciones... de manera más participativa, esas cosas. (Néstor)

Los siguientes ocho códigos, son factores necesarios para el surgimiento de la iniciativa, indistintamente del orden en que los presentamos. El sexto código, solidaridad shipiba, hace referencia a esta característica que se considera como propia del pueblo shipibo, y que, además, se encuentra en el origen de la iniciativa voluntaria 
que surge en el contexto de "la emoción" (sentimiento de empatía con pacientes y sensibilización más allá de la racionalización del problema), y que se expresa en una labor que implica una serie de sacrificios en medio de la emergencia sanitaria.

Hemos tenido que en mayo, junio y julio ha sido el proceso más difícil y voluntariado más quizás uno de los oficios más trabajosos y peligroso que hemos tenido, y nosotros este las 24 horas, así ayudando a las personas sin importar no, las consecuencias hemos roto, hemos hecho nuestro propio protocolo que es conectarnos directamente con el paciente, estar tratando físicamente al paciente, ese era nuestro protocolo, el protocolo de del MINSA de la OMS en algún momento lo hemos tenido pero para nosotros no nos sirvió eso para salvar vidas, y ha sido tan riesgoso y a la vez muy interesante de que había un buen resultado, y ese resultado ahora durante la pandemia ha sido tan positivo, y eso nos garantiza al Comando Matico y estamos un poco en eso, y esa es la historia de cómo comenzó, y nace a la solidaridad, en principio para ayudar el pueblo shipibo pero nos dimos cuenta que la COVID no ataca solamente al pueblo shipibo, sino a los mestizos, a otros pueblos, hicimos para todos $[\ldots]$ y eso es un poco de la historia que te puedo contar, pero detrás de todo ese sacrificio humano que hemos hecho ha sido una tristeza profunda para mí y para los otras personas mis compañeros hemo tenido que sufrir, llorar, cansarnos, anímicamente, físicamente, quizás destruidos, pero nunca hemos bajado la guardia, 4 o 5 integrantes estuvieron con COVID, incluyéndome, y tenía que sentir eso para poder saber cómo era la COVID y fueron momentos muy duros también para mí y para mi familia y para el grupo no, pero siempre hemos estado presente, unidos y ahora estamos acá no, y estamos orgulloso [...] mientras que esté sano, mientras que tengo la necesidad o tengo la suficiente capacidad de ayudar a otra persona, lo voy a hacer, ya será para otra personas o para mi comunidad o para mi pueblo y es por eso que ha nacido este Comando Matico. (Alexander)

El séptimo, es el de la eficacia ancestral, que presenta a la medicina tradicional con la capacidad de trascender las limitaciones de la medicina occidental y de explorar soluciones alternativas. Esta permite también enfrentar el miedo como un mal propio de la misma emergencia sanitaria, ya que daña la salud mental de los pacientes al mismo tiempo que disminuye sus defensas y empeora su estado de salud físico o que les hace más proclives a enfermar a quienes aún no se han contagiado.

Y otra cosa, el miedo es, este virus ha habido mucho miedo no, creo que es otro tema pero personalmente yo he hecho bueno digamos desmayar a seis siete personas no, momento donde que ellos ya no podían resistir y dejaban de respirar no, entonces era estando en el hospital ya le hubiera reportado como fallecido no, pero lo que necesitaba era masajes con plantas, y este pienso

5 Sentimiento de empatía con pacientes y sensibilización más allá de la racionalización del problema. 
que cuando desmayaban era porque el virus digamos salía moría y mataba todo el organismo del cuerpo y le quedaba débil, y la persona quedaba muy agotada muy débil, y ahí es donde que entraba el masaje pues, duraba siete diez minutos, una que duró 10 minutos nos asustó, pensábamos que ya no iba a despertar pero despertó, y así hemos trabajado con los 16 voluntarios. justo pasó algo fuerte no, porque este virus también ha traído bueno nos ha debilitado psicológicamente, sobre todo, físicamente y espiritualmente también, entonces en el pensamiento indígena, algunas personas tenían daño no, ósea brujería, bueno cosas negativas, que fueran, que tienen muchos nombres [...] y este cuando tu masajeas sacabas esa energía negativa y te pasaba (muchas dolencias vinculadas al COVID). (Néstor)

Y yo era muy voluntariosa porque yo practico las plantas medicinales, tomo ayahuasca mucho tiempo también [...] y mi cargo era cuidad en las noches preguntar cómo se sienten porque yo sabía, como este era como miedo en la cabeza [...] y les daba soplo con mapacho, yo tenía mucho tabaco en el local de este COVID, con plantas medicinales, con mapacho, mapacho, protegerlos también [...] como yo practico mucho las plantas medicinales, y entra a soplar con mapacho así ícaros de curaciones y después soplar a esta persona y después se sentían mejor". (Rafael)

El octavo código es el activismo shipibo joven y se refiere al compromiso del voluntariado que les ha permitido varios logros tanto personales como comunitarios. Al mismo tiempo, les brinda capacidad de acción, el mantener una amistad en el tiempo, y retomar entre amigos la solidaridad y las capacidades adquiridas para la gestión durante su activismo adolescente.

El hecho es que él Alexander, él es artista plástico, docente también, desde adolescente hemos hecho teatro y hemos venido participando en políticas públicas de juventud y bueno hemos hecho bastante incidencia, bien unidos no, en ese tiempo éramos dirigentes, pero usábamos el arte para hablar de derechos humanos, medio ambiente, discriminación, tú sabes que a inicios de 2000 los jóvenes de la ciudad estábamos organizando y bueno ha sido un reto pero importante también porque hemos logrado construir este llamado interculturalidad a principios del 2000. Entonces cualquier actividad que hago con él nos hablamos no, si quiere hacer algo también me dice, somos de acción no, sin mucho discurso, entonces me escribió diciendo oye hay que mandar matico a Cantagallo [...] y como no teníamos internet pensamos en Elvio no, un amigo que que también estudia comunicación, Elvio Cairuna [...] con los tres amigos no, y los tres ya hemos venido desde muy adolescente trabajando sobre todo en temas de arte no, bueno también con Jorge Soria hemos fundado bueno conducido programas radiales no, pero lo que ahora sigue vigente es el programa informativo FECONAU, de la federación de comunidades nativas de afluentes del Ucayali, tiene su programa y cuando nosotros éramos voluntarios en FECONAU conseguimos tener ese programa y ahora sigue 
adelante, con Jorge Soria también hemos ganado un premio nacional sobre violencia de género y maltrato físico no, e independientemente yo me gané, bueno fui finalista de varios premios nacionales, bueno algunas cosas que hemos venido haciendo no, me gané una beca de las Naciones Unidas, estuve en varias escuelas de derechos humanos. (Néstor)

El noveno, tomar acción, hace referencia a la disposición del Comando Matico de ir más allá de narrativas-conversaciones-discusiones de sus problemas (que desde hace mucho tiempo llevan a cabo las organizaciones indígenas en distintos conversatorios $\mathrm{y}$ eventos sobre problemas actuales en los que se discuten y denuncian situaciones de vulneración de sus derechos).

El décimo código es el de emergencia y autogestión, y se refiere a la incapacidad del Estado en la Amazonía en medio de la emergencia sanitaria, causando la pérdida de vidas humanas, y la consecuente necesidad de autogestión shipiba.

Una prima murió así, no sé si era el virus, no sé si era el miedo, es que no había nada no, triste no, parece una película...y la preocupación era si la población mestiza que no hay atención, y que no te quieren atender en ningún lugar, el indígena será menos atendido, ósea no sería priorizado, y ahora nuestra preocupación era ahora era quien nos va a atender no...morían personas no, mucha gente sabia, mucha gente joven, y lo que nos movió creo que a todos lo shipibos sobre todo a los artistas fue la muerte de Wilder Agustín Peña, natural de San Francisco pero murió en Cantagallo [...] impulsores no, era músico, joven nomás falleció, y luego creo que todos coincidimos que la muerte de Silvio Valle no, eso fue lo que, como que era, oye ya estamos en finales no? nos vamos a acabar, si el alcalde acaba de morir uno que no es alcalde que es simple ciudadano, no tiene atención no, no había solución, y nosotros pues con la luchas que hemos estado resistiendo, también sabemos nosotros hemos estado también, sabemos que tenemos muchos problemas no, yo digo que hoy es momento de dar solución a los problemas [...] hay un plan de salud (del estado) que no funciona, y si hay un plan no tienen presupuesto a pesar de que la salud es lo más importante en el ser humano. (Néstor)

El empiezo de este pequeño grupo; pues, mis amigos, Jorge Soria, Néstor Paiva, Shimpukat Soria, ellos se habían juntado ya pues, se había unido ya para, ellos más lo que les dolió era cuando murió uno de los shipibos alcalde del distrito de Mayisea (¿?) también habíamos escuchado pues que nuestro hermanos indígenas en Cantagallo en Lima, también estaban ya encerrados no tenían donde que acudir, ya estaban resguardados ellos no podían salir, cómo no, y eso era que nosotros nos unimos, y ya Néstor Paiva tenía mi contacto, con Jorge Soria y Shimpukt no eran tanto pero si nos conocíamos. (Rafael)

El undécimo es el de medios y autogestión, donde se otorga una particular importancia a los medios de comunicación, tanto para conseguir el apoyo necesario para la labor 
del grupo de voluntarios como para la difusión de la iniciativa e incidencia, ya sea radial y/o por medio de internet. Al mismo tiempo, y como se ha visto anteriormente, los medios permiten demandas directas al Estado, que no por esto dejan de ser demandas en busca de autonomía indígena, al menos en lo que concierne al ámbito de la salud. El duodécimo código es el apoyo comunitario, por medio del cual, el grupo de voluntarios sobrevive con la caridad de las personas del lugar, empresarios, las ONG, etc; ya que muchos de los miembros no se encuentran trabajando durante la pandemia. El Estado casi no se ha hecho presente más que con unas cuantas donaciones puntuales y no con un apoyo sostenido. Finalmente, el último código que se encontró es el de la sostenibilidad, y remite a la iniciativa intercultural del Comando Matico del proyecto de construcción de un hospital intercultural shipibo (donde se recoja, revalore y aplique la medicina ancestral desde el conocimiento y experiencia propios shipibos).

A partir de estos códigos podemos comprender de manera amplia como se van conformando las identidades de los jóvenes shipibos del Comando Matico en el mismo proceso de llevar adelante la iniciativa. De cierta manera, el contexto de emergencia sanitaria permitió, como menciona Néstor Paiva, que los conocimientos y capacidades para la autogestión indígena que se gestaron en el activismo adolescente, emergieron y les permite no solo salvar la vida de muchas personas shipibas y no shipibas, sino además pensar y aproximarse a la experiencia de la autonomía indígena, al menos en el ámbito de la salud.

De este modo, se hace evidente cómo el contexto pandémico se vuelve parte esencial de la conformación de las identidades de los jóvenes voluntarios del Comando Matico, que con el soporte y seguridad que les otorgaba el conocimiento de la medicina ancestral logran enfrentar no solo la pandemia, sino también el miedo de aplicar estos conocimientos ancestrales en un contexto de control y vigilancia de parte del Estadoy de las farmacéuticas. En el mismo proceso de respuesta a la emergencia sanitaria se va afirmando la solidaridad shipiba como uno de los rasgos de la identidad de los voluntarios, dado que en adelante y movidos por la misma pondrán en marcha lo aprendido durante su activismo shipibo adolescente, que los reúne y capacita para la gestión social efectiva, y para enfrentar la emergencia desde la autogestión. Esta se da, a su vez, en un contexto en el cual el Estado no solo no logra hacerse responsable de la integridad del pueblo shipibo, sino que además impone un control estatal ineficiente, en el sentido en que se hace necesario tener que burlarlo para poder afrontar la pandemia, posicionándose en contra o resistiéndola con el apoyo de la eficacia ancestral de la medicina tradicional shipiba. Este posicionamiento permite al mismo tiempo que se reafirme el resguardo y aplicación de los saberes ancestrales como otro rasgo importante de su identidad.

Es así como, gracias al uso de los medios - de comunicación- para la autogestión, se logra el apoyo comunitario que les permite a los voluntarios sostener su labor, gracias a la capacidad de tomar acción que en definitiva caracteriza a los miembros 
del Comando Matico. Finalmente, la búsqueda de sostenibilidad de la iniciativa voluntaria los vincula a la búsqueda, en el largo plazo; de la autonomía indígena por medio de la autogestión y resistencia que les ha permitido de cierto modo suplantar en Yarinacocha la responsabilidad estatal de hacerse cargo de la salud e integridad de la población indígena y no indígena en el contexto de la pandemia de COVID-19.

Puede decirse entonces que, la construcción de las identidades de los jóvenes shipibos del Comando Matico en la realidad offline, y desde lo que ellos mismos comprenden al respecto, se reconfigura durante la pandemia de COVID-19 a partir de las experiencias que rodean las actividades de tratamiento de pacientes y la autogestión para sostener esta actividad sin el apoyo del Estado. Estas experiencias les han demandado una dedicación a tiempo completo que los lleva a asumir el rol de voluntarios como su rol principal. De este modo, proponemos que es posible hablar de identidades shipibas de jóvenes activistas voluntarios, lo cual no podría extenderse a la juventud shipiba en general, como en el caso de las características que propone Espinosa en "To be Shipibo Nowadays" (2012), y que no por eso se distancia, sino que más bien se sitúa dentro de estas como su contexto amplio temporal. Los jóvenes shipibos voluntarios del Comando Matico que entrevistamos -tres de sus cinco fundadores- nos hablan de una identidad indígena joven que, a partir de sus experiencias de activismo indígena adolescente, se configura alrededor de cuatro capacidades: de solidaridad shipiba, de autogestión y resistencia, de tomar acción, y de aplicar (reivindicando) sus saberes ancestrales.

La construcción offline de estas identidades implica, además, retomar un vínculo con su tradición oral, con el aprendizaje-exploración y no solo con la aplicación de conocimientos sobre medicina tradicional; sino teniendo, además, la idea de autonomía indígena como uno de los ejes de su autoidentificación.

\section{Conclusiones}

Podemos concluir que las identidades shipibas jóvenes de los miembros del Comando Matico se reconfiguran en el contexto de la pandemia de COVID-19, desde el uso de las nuevas tecnologías de la comunicación, a partir de dos momentos que se tornan espacios sociales en retroalimentación: la auto representación online y la auto identificación offline. Esto concuerda además con la reflexión sobre la pertinencia de entender la identidad de los pueblos indígenas como un fenómeno procesual, en el amplio y complejo espectro temporal de su relación con occidente.

En el primer momento online, estas identidades se configuran buscando lograr la autogestión de la salud comunitaria con el apoyo de la comunidad virtual nacional, a partir de una serie de prácticas de convocatoria y demanda ciudadana pública que se sostiene en formas de auto representación virtual, que a su vez sustentan su llamado a colaborar con ellos: a) como jóvenes, que aunque carecen de medios monetarios 
para su labor, cuentan lo más esencial para su labor que es saber ancestral sobre medicina shipiba (autoidentificación como jóvenes maticos), y b) como jóvenes que ya venían estando comprometidos con su comunidad desde la política o las artes (autoidentificación como jóvenes shipibos activistas). Por otro lado, las dos últimas prácticas de demanda directa al Estado (demanda intercultural y demanda de apoyo), expresan identidades donde tiene lugar una intención, incipiente pero concreta, de autonomía indígena shipiba, al menos en lo que respecta al ámbito de la salud.

En un segundo momento offline, gracias a las entrevistas, nos queda claro que asumen como rol público central o labor a tiempo completo las labores de sanadores y autogestores (jóvenes maticos y jóvenes activistas, capaces y comprometidos). Sus identidades se reconfiguran en el contexto de la pandemia a partir de cuatro capacidades: de solidaridad shipiba, de autogestión y resistencia, de tomar acción y de aplicar sus saberes ancestrales. Estas características que emergen en la situación de crisis que afrontan, se hacen necesarias para sostener lo que aparenta ser una búsqueda progresiva de autonomía. Los jóvenes shipibos del Comando Matico piden obtener el control directo de un espacio intercultural en el que puedan probar su capacidad de reemplazar ellos mismos al Estado a partir de los saberes indígenas ancestrales, al esperar dirigir ellos mismos un hospital intercultural.

De modo que, el momento online -en el que los jóvenes shipibos del Comando Matico se auto representan como jóvenes maticos y activistas, al mismo tiempo que consiguen apoyo para la autogestión- forma parte de un continuum en el que, las auto representaciones registradas virtualmente, son una expresión que conforma a su vez el rol offline de tiempo completo y donde se identifican como jóvenes indígenas capaces de vivir la solidaridad (shipiba), la autogestión y la resistencia, y en el que pueden tomar acción y aplicar sus saberes ancestrales. No hay que dejar de notar que la clara tendencia a la autonomía que resalta en su propia demanda intercultural no implica en absoluto que dejen de haber demandas prácticas al Estado, como en el caso de la propuesta intercultural de AIDESEP, su iniciativa busca una integración que requiere de y demanda los recursos del Estado peruano. La presencia de este a partir de la misma autonomía para dirigir el proceso de desarrollo intercultural de la salud parece ser lo más pertinente, tomando en cuenta tanto la efectividad que ha tenido el trabajo de estos jóvenes voluntarios como el precedente positivo del programa de enfermeros interculturales del AIDESEP.

Finalmente, la forma en que se configuran las identidades de los jóvenes shipibos del Comando Matico nos deja notar una continuidad interesante con respecto a lo que se ha indagado con anterioridad con respecto a las identidades indígenas. Nos referimos a que, la participación en organizaciones de jóvenes que les ha servido para afrontar de manera activa el desfase intergeneracional, fenómeno social relativamente reciente en la Amazonía (Espinosa, 2019) y que les ha capacitado, a su vez, para la gestión cultural y social (Espinosa, 2012) al haberles preparado para pensar tanto como para buscar una autonomía indígena shipiba en el ámbito de la salud. En el caso de los 
jóvenes shipibos miembros de este colectivo de voluntarios, el dilema entre ser o no indígena, que a veces surge de la relación con el mundo mestizo, parece haber sido dejado de lado. En su lugar, el caso particular que estudiamos nos muestra que en un contexto adverso se dan las condiciones para que surja una autoidentificación indígena íntimamente vinculada con las ideas de resistencia y autonomía indígena, así como con la capacidad de los conocimientos ancestrales de enfrentar la emergencia sanitaria, y que, al volverse esencial para la autogestión, se convierte en fuente de una identidad política que se sostiene sobre la probada eficacia del saber ancestral (en este caso la medicina tradicional shipiba) para enfrentar la crisis sanitaria actual. 


\section{Referencias bibliográficas}

Cárdenas, C. (2017). Interculturalidad en salud: reflexiones a partir de una experiencia indígena en la Amazonía peruana. Anthropológica, 35(39), 151-169. http://www.scielo.org. pe/scielo.php?pid=S0254-92122017000200007\&script=sci_abstract

Clavijo, C. (2011). Sistemas médicos tradicionales en la Amazonia nororiental: salud y saberes alternativos. Iatreia, 4(1), 5-15. https://revistas.udea.edu.co/index.php/iatreia/article/ view/8426

Díaz Caravantes, E. (2018). Vulnerabilidad y riesgo como conceptos indisociables para el estudio del impacto del cambio climático en la salud. Sonora: Centro de Estudios en Salud y Sociedad del Colegio de Sonora.

Dietz, G. (1999). Etnicidad y cultura en movimiento. Desafíos teóricos para el estudio de los movimientos étnicos. Nueva Antropología, 17(56), 81-107. https:/www.redalyc.org/ pdf/159/15905606.pdf

Espinosa, O. (1998). Los pueblos indígenas de la Amazonía peruana y el uso político de los medios de comunicación. América Latina Hoy, 19. https://revistas.usal.es/index.php/11302887/article/view/2258

Espinosa, O. (2012). To Be Shipibo Nowadays: The Shipibo-Konibo Youth Organizations as a Strategy for Dealing with Cultural Change in the Peruvian Amazon Region. The Journal of Latinamerican and Caribbean Anthropology, 17.

Espinosa, O. (2019). Dilemas de la juventud indígena amazónica en el Perú. Intercambio, (47).

Hine, C. (2014). Etnografía virtual.

Kelly, J. (2009). Equívocos sobre identidad y cultura: un comentario sobre la formulación de políticas para los pueblos indígenas en Venezuela.

Kopenawa, D. \& Bruce, A. (2013). The falling sky, words of a yanomami shaman. Anuac, $3(2), 122-124$.

LeCompte, M. \& Schensul, J. (1999) Analyzing and Interpreting Ethnographic Data. CA: Press.

MIDIS (2019). La Nueva Politica Social: Orientaciones, Procesos y Desafios. Dirección General de Políticas de Desarrollo Social.

Pink, S. (2013). Engaging the Senses in Ethnographic Practice: Implications and advances. The Senses and Society, 8(3), 261-267. https://www.tandfonline.com/doi/ pdf/10.2752/174589313X13712175020433

Pink, S. (2016). Digital Ethnography: Principles and Practice. Los Angeles; London: SAGE. 
Ramos, R. (1992). The hypperreal indian. Crítica de la antropología , 14 (2), 153-171. https://doi.org/10.1177/0308275X9401400203

Scaletzky, I. (2001). La Educación Intercultural Bilingüe en la Amazonía Peruana: políticas culturales de un Estado Nacional en crisis, en el marco de la globalización. Ensayo publicado en Actas del Congreso de ADHILAC, Pontevedra.

Vásquez, S \& Gómez, G. (2006). Autogestión Indígena en Tlahuitoltepec Mixe, Oaxaca, México. Ra Ximhai, (2),1, 151-169. https://www.redalyc.org/pdf/461/46120108.pdf 